\title{
К проблеме генезиса массива Ярва-варака (Мончегорский рудный район)
}

\author{
Нерович Л.И., Баянова Т.Б., Кунаккузин Е.Л., Елизаров Д.В., Базай А.В. \\ Геологический институт КНЦ РАН, Anamumb, nerovich@geoksc.apatity.ru
}

Аннотация. В работе приведены результаты изотопно-геохимических (U-Pb, Sm-Nd, Rb-Sr) исследований пород массива Ярва-варака, которые показали уверенный вклад коровой компоненты в источник только для наиболее насыщенных гранофиром разностей интрузива. Остальные же породы, согласно полученным характеристикам, имеют либо мантийный источник, либо мантийный источник, очень слабо обогащенный коровой компонентой, менее чем в других палеопротерозойских интрузиях Балтийского щита. При этом только в массиве Ярва-варака гранофир широко представлен по всему разрезу магматического комплекса, начиная с предполагаемого дна магматической камеры. Учитывая показанное ранее сходство разреза и пород массивов Ярва-варака и Садбери на первый план выходит проблема генезиса интрузива и методические аспекты исследования подобных сложных объектов.

Ключевые слова: массив Явра-варака; гранофировые породы; изотопно-геохимические исследования; природа источников исходных расплавов.

\section{On the problem of the Jarva-varaka massif genesis (Monchegorsk ore area)}

\author{
Nerovich L.I., Bayanova T.B., Kunakkuzin E.L., Elizarov D.V., Bazay A.V. \\ Geological institute KSCRAS, Apatity,nerovich@geoksc.apatity.ru
}

\begin{abstract}
Results of isotope-geochemical (U-Pb, Sm-Nd, Rb-Sr) studies of the Jarva-varaka massif rocks are presented in this paper. This data point to significant contribution of the crustal component in the mantle source only for intrusive rocks saturated by granophyre. According to new data, another rocks of the massif have either a mantle source, or a mantle source poorly enriched by crust component in comparison with other Paleoproterozoic intrusions in the Baltic Shield. It must be emphasized that only in the Jarva-varaka magmatic complex granophyre is widely represented throughout the section from the probable bottom of the magmatic chamber. Considering similar sections of the Jarva-varaka and Sudbury massifs and rocks, the problem of the intrusion genesis and the methodological aspects of the study of such complex objects becomes vital.
\end{abstract}

Key words: Jarva-varaka massif; granophyre rocks; isotope-geochemical studies; nature of source melts.

\section{Введение}

Массив Ярва-варака находится в пределах Мончегорского рудного района, к северо-западу от г. Мончегорска на юго-восточном берегу оз. Мончеозеро. Массив представляет собою интрузивное тело неправильной формы размером в плане $1.7 \times 2.2$ км и мощностью до 2 км. Массив сложен норитами двух типов, гиперстеновыми диоритами, пижонит-авгитовыми диоритами, кварцевыми диоритами и гранодиоритами. Нориты различаются по обилию ортопироксена (мафитовые нориты) или плагиоклаза (фельзитовые нориты). По разрезу структурной скважины 1300 глубиной 2 км преобладают фельзитовые нориты и гиперстеновые диориты. Возраст кварцевых диоритов определен в $2496 \pm$ млн. лет, $\varepsilon_{\mathrm{Nd}}=-2.48$ (Расслоенные интрузии..., 2004). Вмещающими породами являются глиноземистые гнейсы кольской серии. Вблизи массива они имеют порфирокластические структуры, здесь много брекчированных пород.

Наиболее яркой особенностью массива Ярва-варака является присутствие во всех разновидностях, слагающих его пород, значительной доли гранофировой составляющей. Гранофир или микропегматит часто наблюдается в породах расслоенных комплексов, но, как правило, он составляет доли процента общего объема породы. В Мончегорском районе гранофировые породы наблюдаются в прикровлевой зоне Имандровского лополита. Кварцевые диориты данного массива рассматриваются как продукты кристаллизации остаточного расплава, а более кислые гранофиры считают 
результатом плавления кислых вулканитов кровли под термальным воздействием основной магмы интрузива (Расслоенные интрузии..., 2004). В Бушвельдском лополите гранофировые породы, соответствующие по составу ферродиоритам и феррогаббро находятся в верхней части Верхней зоны массива. Большинство исследователей считают, что они являются продуктом кристаллизации остаточной магмы Бушвельдского массива (Налдретт, 2003). Гранофировые ферродиориты Скергаардского интрузива наблюдаются в верхней части расслоенной серии. Во всех перечисленных массивах гранофировые породы располагаются в верхней части разреза. Во всех комплексах соблюдается пропорция между общим объемом пород интрузивов и объемом гранофировых пород. Этих пород должно быть достаточно для производства в процессе дифференциации соответствующего количества остаточного расплава или для мощного термального воздействия на породы кровли. Массив Ярва-варака явно отличается от вышеперечисленных комплексов, в нем слишком много гранофира и он присутствует, начиная с предполагаемого дна магматической камеры.

Ранее было показано, что по присутствию значительной доли гранофира во всех породах интрузива начиная с основания магматического комплекса, по мощности этого магматического комплекса и по петрографическому и геохимическому составу пород массив Ярва-варака наиболее близок к массиву Садбери (Нерович и др., 2015). В настоящее время доминирует точка зрения, что структура Садбери представляет собой остатки крупного многокольцевого ударного бассейна (Налдретт, 2003). Предполагается, что при формировании комплекса Садбери происходило переплавление и контаминация больших масс корового материала так называемой «мишени».

\section{Изотопно-геохимические исследования пород массива Ярва-варака}

$\mathrm{U}-\mathrm{Pb}, \mathrm{Sm}-\mathrm{Nd}$ и Rb-Sr изучение пород выполнено в Кольском ЦКП (г. Апатиты).

$\mathrm{U}-\mathrm{Pb}$ исследования проведены для мафитовых норитов интрузива, которые сложены ортопироксеном (40 \%), плагиоклазом (40\%), гранофиром (Pl+Kfs+Qtz) (15\%). Вторичные минералы представлены биотитом $(\leq 1 \%)$, тальком, эпидотом, акцессорные минералы - апатитом, рудным минералом (до 5 \%), монацитом, цирконом, бадделеитом и циркелитом. При изучении положения цирконовых минералов в мафитовых норитах выявлено, что все они локализованы в гранофировой составляющей породы. Циркон часто наблюдается вместе с апатитом и в сростках с монацитом. Кроме того сравнительно крупные зерна переотложенного циркона присутствуют в микроксенолитах, которые неравномерно распространены в мафитовых норитах. Размеры зерен циркона здесь крупнее или сопоставимы с зернами шпинели и секут границы других минералов из микроксенолита. Для бадделеита очень характерна ассоциация с ильменитом, апатитом и циркелитом. Реже оба минерала располагаются внутри чешуек биотита.

Для U-Pb датирования были отобраны следующие навески:

1. Бадделеит представлен непрозрачными обломками коричневого цвета, с корродированной поверхностью. В бадделеите выявлена внутрифазовая неоднородность (зональность) и крупные вростки породообразующих минералов (фазовая неоднородность).

2. Призматические кристаллы циркона светло-коричневого цвета. Зерна прозрачные и полупрозрачные, поверхность зерен слабо корродированная. Блеск стеклянный. В кристаллах слабо проявлена ритмичная зональность внутренних участков кристаллов. В цирконе диагностированы включения Al-силиката (силлиманит). Циркон не обладает CL-свечением.

3. Призматические кристаллы и обломки циркона светло-желтого цвета. Зерна прозрачные. Поверхность зерен слабо корродированная. Блеск стеклянный. Кристаллы имеют грубую зональность с выделением трех зон: внутренней, промежуточной и внешней. Внутренняя зона характеризуется ритмичной зональностью с нечеткими контурами и фазовой неоднородностью (включения). К границе между внутренней и промежуточной зонами приурочены участки изменения циркона. В промежуточной зоне проявлена четкая ритмичная зональность с разной шириной зон, контуры зон идиоморфны. Внешняя зона не проявляет признаков внутрифазовой неоднородности. К отдельным зонам приурочены включения (фазовая неоднородность) и участки изменения циркона. Среди включений диагностированы Al-силикат (силлиманит) и предположительно плагиоклаз. 
4. Длиннопризматические кристаллы циркона коричневого цвета. Зерна полупрозрачные, поверхность корродированная, блеск стеклянный. В цирконе слабо проявлена ритмичная зональность. Контуры зон гипидиоморфные и идиоморфные, в целом совпадают с внешней огранкой кристаллов. Кристаллы содержат крупные вростки минералов (фазовая неоднородность), среди которых диагностирован Al-силикат (силлиманит).

5. Обломки циркона светло-желтого цвета. Зерна прозрачные, поверхность слабо корродированная, блеск стеклянный. В цирконе выявлена ритмичная зональность с разной шириной зон, нечеткими границами и идиоморфными контурами. Кристаллы сильнотрещиноватые, к трещинам приурочены участки изменения циркона.

Для бадделеита и циркона 2 и 3 была получена изохронна с верхним пересечением $2550 \pm 9$ млн. лет при конкордантном положении бадделеита. Нижнее пересечение $-402 \pm 83$ млн. лет соответствует палеозойским событиям. Цирконы 4 и 5 попали на конкордию $-2610 \pm 3$ млн. лет и признаны ксеногенными (рис. 1).

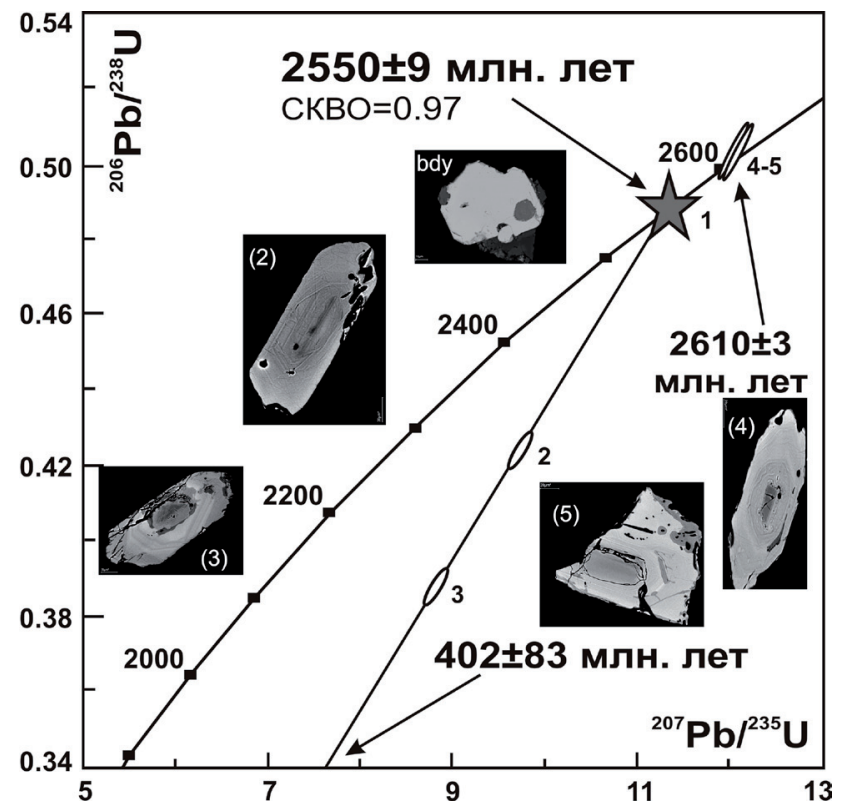

Рис 1. U-Pb изохронная диаграмма для бадделеита (1) и циркона (2-5) из мафитовых норитов массива Ярваварака (проба НВ-1/114).

Fig.1. U-Pb isochrones on baddeleyite (1) and zircons (2-5) from the Jarva-varaka massif mafic norites (sample HB-1/114).
Таким образом, учитывая ранее установленный возраст кварцевых диоритов $2496 \pm 9$ млн. лет (Расслоенные интрузии..., 2004), по-видимому, мафитовые нориты представляют собой самостоятельную фазу. Полученная датировка согласуется с данными геохимии о положении данных пород вне общего тренда фельзитовые нориты - гранодиориты (Нерович и др., 2015). На данном этапе возраста 2.5 и 2.55 млрд. лет принимается для последующих расчетов результатов $\mathrm{Sm}-\mathrm{Nd}$ и $\mathrm{Rb}-\mathrm{Sr}$ исследований. Но такие факты как локализация цирконовых минералов только в гранофировой части, присутствие внутрифазовой неоднородности в бадделеите, грубая зональность циркона 3 и включения силлиманита оставляют вопросы. Кроме того, кристаллы циркона из мафитовых норитов показывают изменение рамановских спектров от ядерных частей зерен, которые сохраняют типичный для циркона набор пиков, до полного отсутствия спектральных полос в периферических частях и каймах. Минеральные включения в каймах циркона также демонстрируют отсутствие рамановских пиков. Согласно (Каулина и др., 2017), такие вариации спектров могут быть связаны с преобразованием кристаллического циркона (и минеральных включений в нем) в диаплектовые стекла вследствие ударного метаморфизма, внутренние же части циркона экранировались каймами и сохранили свою структуру. Все это указывает на необходимость исследования единичных зерен циркона высокотехнологичными методами (SRIMP).

На настоящий момент $\mathrm{Sm}-\mathrm{Nd}$ и $\mathrm{Rb}-\mathrm{Sr}$ методами изучены все разновидности пород массива кроме гранодиоритов. Наиболее низкие значения $\mathrm{I}_{\mathrm{Sr}}$ получены для Pgt-авгитовых диоритов (0.7010) и фельзитовых норитов $(0.7019$ и 0.7025$) . \mathrm{I}_{\mathrm{Sr}}$ мафитовых норитов $-0.7025,0.7032$ и 0.7035 , гиперстеновых диоритов - 0.7023 и 0.7041. Устойчиво выше значение $\mathrm{I}_{\mathrm{Sr}}$ у кварцевых диоритов - 0.7043 и 0.7047 (рис. 2). Результаты показывают, что источник расплавов кварцевых диоритов немного обогащен, что может быть связано с умеренной контаминацией коровым материалом. Остальные породы имеют мантийные характеристики $\mathrm{Rb}-\mathrm{Sr}$ системы. 


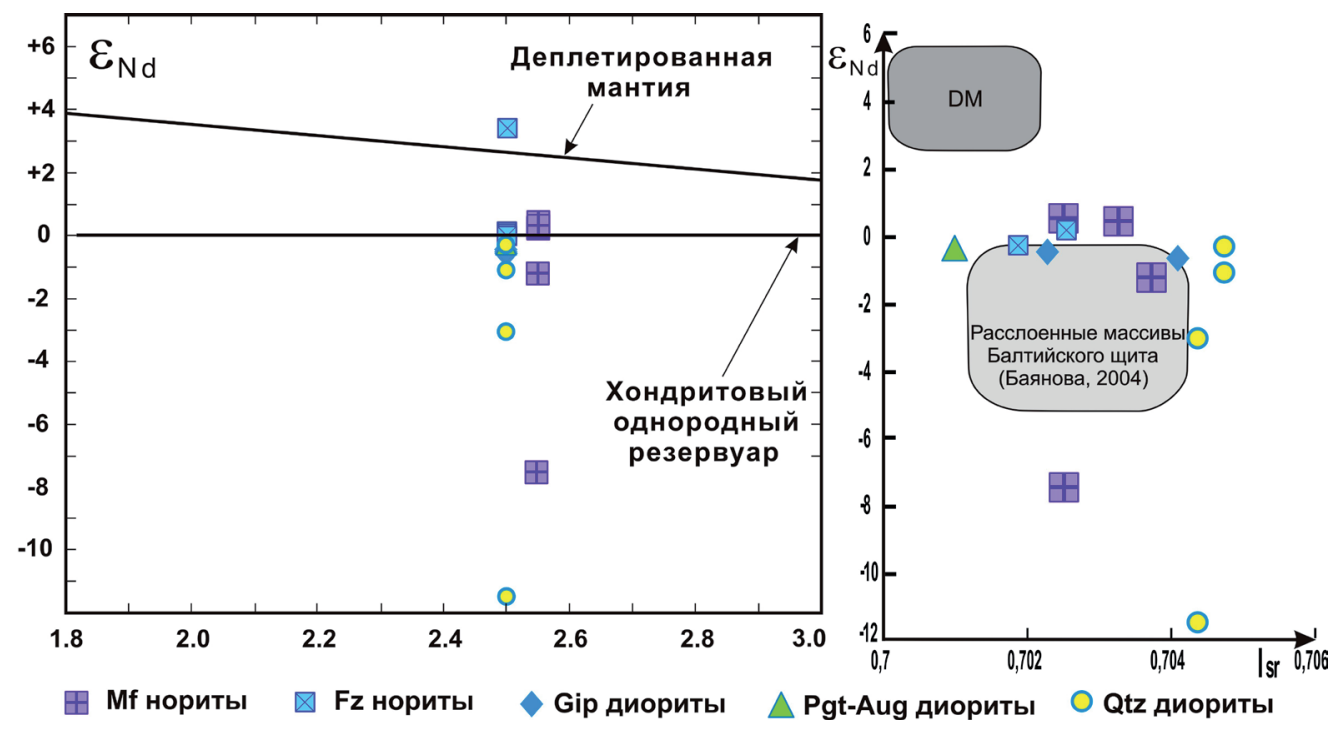

Рис. 2. Диаграммы $\varepsilon_{\mathrm{Nd}}$-время и $\varepsilon_{\mathrm{Nd}}-\mathrm{I}_{\mathrm{Sr}}$ для пород массива Ярва-варака.

Fig. 2. The $\varepsilon N d-T$ and $\varepsilon N d-I S r$ diagrams for the Jarva-varaka massif rocks.

Результаты Sm-Nd исследований носят очень противоречивый характер. Для двух образцов: мафитового норита и кварцевого диорита были получены значения $\varepsilon_{\mathrm{Nd}}--7.49$ и -11.46 соответственно при не очень корректном отношении ${ }^{147} \mathrm{Sm} /{ }^{144} \mathrm{Nd}=0.14$. Впоследствии для этих же пород получены значения $\varepsilon_{\mathrm{Nd}}-+0.43$ и -3.02 , отношение ${ }^{147} \mathrm{Sm} /{ }^{144} \mathrm{Nd}=0.11$. На рисунке 2 видно, что большинство полученных значений $\varepsilon \mathrm{Nd}$ имеет слабоположительные и слабоотрицательные значения, располагающиеся либо в верхней части поля составов палеопротерозойских интрузий Балтийского щита, либо выше. А для одной из проб фельзитовых норитов получено значение $\varepsilon \mathrm{Nd}=+3.57$, отвечающее деплетированной мантии. Таким образом, большая часть $\mathrm{Sm}-\mathrm{Nd}$ и $\mathrm{Rb}-\mathrm{Sr}$ данных указывает на мантийный источник. Только для кварцевых диоритов устойчивость отрицательных значений $\varepsilon \mathrm{Nd}(-3.02,-1.07,-0.32)$ в совокупности с $\mathrm{I}_{\mathrm{Sr}}$ устойчиво превышающим значение 0.704 можно уверенно говорить коровой контаминации источника.

\section{Обсуждение результатов}

$\mathrm{Sm}-\mathrm{Nd}$ и $\mathrm{Rb}-\mathrm{Sr}$ изотопно-геохимические данные для полученных цифр возраста показывают умеренную контаминацию коровым материалом источника кварцевых диоритов. Мафитовые нориты, Pgt-авгитовые диориты и преобладающие в массиве фельзитовые нориты и гиперстеновые диориты, согласно этим данным кристаллизовались из эволюционирующего мантийного расплава, из его обогащенной остаточной части. Учитывая объем остаточного расплава можно рассмотреть следующие варианты его происхождения:

- Под массивом Ярва-варака находится гигантское ультрамафит-мафитовое глубинное тело, в процессе дифференциации которого возник большой объем обогащенного расплава. В верхней зоне Бушвельда мощность ферродиоритов достигает 1500 м при полной мощности разреза 7-9 км. Мощность ферродиоритов Сандвичевого горизонта в 3.5-километровом разрезе Скергаарда составляет 200 м. Даже Бушвельд не произвел двух километров обогащенных пород. Кроме того существуют ограничения по геофизическим данным (Филатова, 1995) и данным бурения структурной скважины.

- Массив Ярва-варака - это верхняя зона для всех массивов Главного хребта и Мончеплутона по аналогии с ферродиоритами верхней зоны Бушвельда. Как известно Е.В. Шарков рассматривал эти массивы как единый комплекс типа Бушвельда (Шарков, 1980). Весь остаточный расплав в таком случае должен быть вытеснен в отдельную камеру и далее мог, как эволюционировать, так и воздействовать на породы кровли. Это не может быть тектоническим срывом верхней части разреза, так как в норитах присутствуют ксенолиты глиноземистых гнейсов, которые не характерны для обрамления других массивов Мончегорского района. Мощность полного разреза Главного хребта и 
Мончеплутона сопоставима с разрезом Бушвельда. Однако нужно учесть, что в каждом из интрузивов установлен существенный объем своих продуктов остаточного расплава - габбро-пегматитов. Во всяком случае, их количество в Мончетундровском массиве и особенно в Мончеплутоне соответствует объему самих интрузивов.

- Неправильно оценена мощность массива. Т.е. это не единый разрез, а серия надвинутых друг на друга тектонических пластин. Это тоже потребует наличия глубинного тела, но разумных размеров. Никаких данных, геологических или геофизических, склоняющих к этой точке зрения нет. Милонитизированные гнейсы наблюдаются в обрамлении интрузива. В структурной скважине милониты и катаклазиты по диоритам массива иногда отмечаются только в интервале 70-117 м. В ходе текущих исследований наблюдали только массивные разности пород массива.

Все три рассмотренные возможности получить 2 км разреза гранофировых пород из мантийного источника, представляются мало реализуемыми. Наличие гранофира на дне магматической камеры и далее вверх по разрезу реальнее объяснить импактным событием с плавлением основного и кислого материала в мишени и последующей кристаллизацией. Кроме изотопных характеристик, $\varepsilon \mathrm{Nd}$ в массиве Садбери обычно составляет $-6 \div-9$, основным препятствием является форма массива Ярва-варака. Если мощность разреза магматического комплекса в обоих интрузива составляет $\sim 2$ км, то площадь развития пород в них несопоставима. В Садбери породы простираются более чем на 100 км. Второй теоретически возможный механизм - катастрофически быстрое поступление разогретой базитовой магмы в верхнюю кору, взрыв и образование депрессии с обрушением значительных объемов пород кровли. Т.е. это похоже, но не идентично классической трубке взрыва. Разные источники и разные глубины, с которых выносится вещество. Второй механизм более согласуется с небольшими по площади размерами массива Ярва-варака. Установленные в цирконе признаки диаплектовости могут наблюдаться в обоих случаях. Но Садбери на сегодняшний день является общепризнанной импактной структурой, а уровень сходства достаточен, чтобы предполагать и сходство механизмов образования Садбери и массива Ярва-варака.

Работа выполнена в рамках Госзадания ГИ КНЦ РАН, тема НИР № 0226-2019-0053.

\section{Литература}

1. Баянова Т.Б. Возраст реперных геологических комплексов Кольского региона и длительность процессов магматизма. СПб.Изд-во: Наука. 2004. 174 с.

2. Каулина Т.В., Нерович Л.И., Бочаров В.Н., Лялина Л.М., Ильченко В.Л., Кунаккузин Е.Л., Касаткин И.А. Рамановская спектроскопия импактного циркона из расслоенного массива Ярва-варака (Мончегорский рудный район, Кольский полуостров) // Вестник МГТУ. 2017. Т. 20. № 1/1. С. 72-82. DOI:10.21443/15609278-2017-20-1/1-72-82.

3. Налдретт А. Дж. Магматические сульфидные месторождения медно-никелевых и платинометальных руд. СПб. Изд-во: СПбГУ. 2003. 487 с.

4. Нерович Л.И., Баянова Т.Б., Кунаккузин Е.Л., Базай А.В., Некипелов Д.А. Новые результаты геологопетрографического и петро-геохимического изучения расслоенного массива Ярва-Варака (Мончегорский рудный район) // Труды XII Всероссийской (с международным участием) Ферсмановской научной сессии, посвящённой 80-летию со дня рождения акад. РАН Ф.П. Митрофанова. Апатиты, 6-7 апреля 2015 г. C. $141-146$.

5. Расслоенные интрузии Мончегорского рудного района: петрология, оруденение, изотопия, глубинное строение (ред. Ф.П. Митрофанов, В.Ф. Смолькин). В 2 частях. Апатиты. Изд-во: КНЦ РАН. 2004. 177 с.

6. Филатова В.Т. Объёмная модель Мончегорского рудного района на основе гравимагнитных данных // Отечественная геология. 1995. ․ 10. С. 65-72.

7. Шарков Е.В. Петрология расслоенных интрузий. Л. Изд-во: Наука. 1980. 184 с. 